\title{
A review of basic well log interpretation techniques in highly deviated wells
}

\author{
Sayantan Ghosh $^{1}$ (D)
}

Received: 21 August 2021 / Accepted: 20 December 2021 / Published online: 4 January 2022

(c) The Author(s) 2022

\begin{abstract}
Drilling deviated wells has become customary in recent times. This work condenses various highly deviated and horizontal well log interpretation techniques supported by field examples. Compared to that in vertical wells, log interpretation in highly deviated wells is complex because the readings are affected not only by the host bed but also the adjacent beds and additional wellbore-related issues. However, understanding the potential pitfalls and combining information from multiple logs can address some of the challenges. For example, a non-azimuthally focused gamma ray logging while drilling (LWD) tool, used in combination with azimuthally focused density and neutron porosity tools, can accurately tell if an adjacent approaching bed is overlying or underlying. Moreover, resistivity logs in horizontal wells are effective in detecting the presence of adjacent beds. Although the horns associated with resistivity measurements in highly deviated wells are unwanted, their sizes can provide important clues about the angle of the borehole with respect to the intersecting beds. Inversion of horizontal/deviated well logs can also help determine true formation resistivities. Additionally, observed disagreement between resistivity readings with nuclear magnetic resonance (NMR) T2 hydrocarbon peaks can indicate the presence or absence of hydrocarbons. Furthermore, variations in pulsed neutron capture cross sections along horizontal wells, measured while injecting various fluids, can indicate high porosity/permeability unperforated productive zones. Finally, great advances have been made in the direction of the bed geometry determination and geologic modeling using the mentioned deviated well logs. More attention is required toward quantitative log interpretation in horizontal/high angle wells for determining the amount of hydrocarbons in place.
\end{abstract}

Keywords Horizontal $\cdot$ Formation evaluation $\cdot$ Well logging $\cdot$ Deviated $\cdot$ Tool response

\begin{tabular}{ll}
\multicolumn{2}{l}{ Abbreviations } \\
GR & Gamma ray \\
ILd (ILD) & Deep reading induction log \\
ILm (ILM) & Medium reading induction log \\
ILs (ILS) & Shallow reading induction log \\
LWD & Logging while drilling \\
MWD & Measurement while drilling \\
NMR & Nuclear magnetic resonance \\
Kpsw & $\begin{array}{l}\text { Neutron capture cross section while injecting } \\
\text { seawater }\end{array}$ \\
$\sum$ pbw & Neutron capture cross section while injecting \\
& borax waters \\
PNC & Pulsed neutron capture \\
RA & Resistivity attenuation
\end{tabular}

Sayantan Ghosh

ghoshsayantan88@gmail.com; sayantan@iitism.ac.in

1 Department of Petroleum Engineering, IIT(ISM), Dhanbad, India

$\begin{array}{ll}\text { RP } & \text { Resistivity phase shift } \\ \text { TPHI } & \text { Total porosity from pulsed neutron tool } \\ \text { T1 } & \text { Buildup rate of longitudinal magnetization in } \\ & \text { NMR tool } \\ \text { T2 } & \text { Rate of transverse magnetization decay in } \\ & \text { NMR tool }\end{array}$

\section{Introduction}

Horizontal drilling technology attained commercial success during the late 1980s in the Bakken Shale of North Dakota and the Austin Chalk of Texas ("Drilling sideways", 1993). The main objective of horizontal wells is to bring the maximum possible volume of the intended reservoir rock in contact with the wellbore. Also, it is very important to understand the lithology and fluid content of the target formation. However, our understanding of horizontal well log interpretation is yet to catch up with the pace at which these 
wells are being drilled. Commonplace methods to understand the lithology and the fluid content are core testing, seismic interpretation, and well log interpretation. This work focuses on the well log interpretation part, especially horizontal and highly deviated wells, as that is very challenging and prone to misinterpretations.

In vertical wells, the logging tools run perpendicular to the bedding planes and record the lithology of the host bed, the formation fluids, and the invading fluids. These three factors also affect log readings in deviated and horizontal wells. However, if a horizontal well is drilled in a thin layer or if its trajectory is located too close to a surrounding bed, the surrounding beds can have considerable influence on the log responses (Singer 1992). This phenomenon, however, can be used to approximate the reservoir cross section, which provides an estimate of reservoir volume. Passey et al. (2005) mentioned that the application of vertical well log interpretation methodology to horizontal wells can result in porosity calculation errors up to $6 \%$, water saturation uncertainty up to 50\%, and true stratigraphic thickness errors of up to $300 \%$. Therefore, interpretation in horizontal wells requires additional knowledge about the nature of the adjacent beds and their influence on the logs. To avoid some of the problems associated with log interpretation in horizontal wells, Rogtec (2017) advocates for tools with azimuthal measurements capacities. Valdisturlo (2013) mentioned that nodules, often intersected on one side of the borehole, could lead to scattering in density-neutron porosity crossplots if the neutron porosity measurement is non-azimuthal and the density measurement is azimuthal. Li et al. (2018) showed a method to calculate porosity from sonic logs acquired from horizontal wells. Market and Canady (2009), Wang et al. (2015a, b), and Kinoshita et al. (2016) deal with sonic long interpretation and sonic anisotropy problems in detail.

Several researchers have earlier used horizontal and highly deviated wells $\operatorname{logs}$ to ascertain various reservoir attributes. For example, Xu and Stewart (2004) used a seismic $\mathrm{Vp} / \mathrm{Vs}$ map along with gamma ray (GR) logs from horizontal wells to identify a shale body within a target sand. Thorsen et al. (2010) used the NMR tool in chalk formations in horizontal wells to estimate the hydrocarbon potential in a North Sea field. King (2018) demonstrated the efficient exploitation of hydraulic fracturing stages from an accurate estimation of formation properties from horizontal well logs.

Resistivity logs are commonly used in formation evaluation. However, interpreting these logs in highly deviated wells has its own set of challenges. Propagation resistivity tools consist of one or multiple phase shift and attenuation readings. Generally, in layered rocks, series circuit resistivity is higher than parallel circuit resistivity. Surrounding beds and apparent dip have a higher impact on attenuation resistivity. Phase shift resistivity reads shallower, has better vertical resolution, and is more affected by anisotropy. Wang et al. (2021) provided a method for a real-time forward and inverse modeling method of logging while drilling (LWD) electromagnetic logs to process the field data to solve bed boundary prediction problems in horizontal wells, which helps in optimizing the well trajectory. Moreover, Syofyan et al. (2017) showed a method of inverting apparent short- and long-spaced phase difference and attenuation data to obtain the true resistivity of a Cretaceous carbonate reservoir. Mahiout et al. (2020) described an advanced resistivity processing workflow for low angle and high angle wells in wireline and LWD tools. They showed that saturation calculations using modeled or corrected true resistivities are more accurate compared to measured resistivities in highly deviated wells because measured resistivity has shoulder bed effects in addition to invasion. Valdisturlo et al. (2013) mentioned asymmetric invasion profiles and segregation of drilled cuttings as challenges in the interpretation of resistivity logs in horizontal wells. In addition, Ortenzi et al. (2012), Wen et al. (2013), and Sun et al. (2014) have addressed various issues related to the usage and interpretation of resistivity logs in horizontal wells.

Integration of horizontal well $\log$ information into a 3D model is an ongoing complicated issue (Worthington 2008). However, for geologic modeling, Polyakov et al. (2013) used an algorithm that yields reservoir structure and properties near the wellbore from high angle and horizontal well log data. Subsequently, the 3D geological models initially obtained from seismic and vertical well data were automatically updated from the log information. They further used these models for history matching and other reservoir management decision making, with a goal to substantially increase the reservoir yield. Liu et al. (2015) used horizontal well logs in combination with two offset vertical wells and achieved consistent geological interpretation. In addition to the knowledge of formation structure, they used their knowledge of tool response with commonly observed horizontal log anomalies, such as borehole-deviation effect, shoulder effect, and resistivity anisotropy effect, to achieve this feat. Approaching bed boundaries were mainly observed through deep-looking resistivity tools and helped locate the bit with respect to the target fracable zone. Omeragic et al. (2013) also devised a method to update geologic information derived from horizontal and deviated well logs information for use in geosteering wells. According to Rogtec (2017), accurate geologic models can be built using pre-drill seismic data in combination with data obtained from horizontal and deviated wells.

Image logs, though not as commonly obtained as other geophysical logs, provide a plethora of subsurface information. One of the major purposes of image logs is to understand subsurface bedding features when cores are not available. Another major utility of image logs in the oil industry, especially in unconventional shales and tight formations, is 
to image natural fractures. Imaging horizontal and highly deviated logs using wireline has been a challenge because of tool eccentricity issues and difficulty in moving the tool. Additional challenge lies in using resistivity image logs, as these logs do not perform well in wellbores containing oilbased mud. Many unconventional shale wells require oilbased mud to avoid clay swelling. Thus, the requirement of image logs for natural fracture imaging in unconventional reservoirs and simultaneous use of oil-based mud transgress each other's purposes. To avoid these issues, LWD, in combination with acoustic imaging, is being used in recent years (Amorocho et al. 2019; Morys et al. 2018). Rotation of the drillstring helps the acoustic tool image the entire wellbore circumference, reducing dependency on resistivity image logging. Milad et al. $(2018,2020)$ presented methods of building geological and DFN reservoir models (for hydrocarbon production simulation) with the help of image logs from horizontal wells and petrophysical logs from vertical wells.

This work does not present new data. Rather a summary of existing works for a curious, general audience has been presented in a lucid manner. This work is also intended to be useful for industry personnel, embarking into their log interpretation journey, for awareness about peculiar ways in which commonly obtained logs behave in deviated and horizontal wells. The intended layout is to (a) present responses of various wireline and measurement while drilling (MWD) $\log$ s to explain how these logs behave in the presence of adjacent beds and other situations encountered in horizontal wells; (b) present case studies demonstrating the applications of petrophysical logs in horizontal and highly deviated wells; (c) discuss the value of currently existing workflows and propose possible areas of improvement. As a word of note, this work does not delve into production logging; it is confined to formation evaluation. Regarding sonic log interpretation and anisotropy, these are extensive topics on their own right that require at length discussion, and hence have not been addressed in this review.

\section{Theory of tool response in horizontal and highly deviated wells}

\section{Gamma ray log}

Early GR tools did not focus in one direction but gathered signals from all radial directions. For horizontal wells, this translates to incoming signals from both above, below, and sides of the wellbore. Ninety percent of the signal for the GR reading comes from within eight inches of the wellbore. The GR reading is a function of true GR reading from the target formation, surrounding beds, wellbore radius, and distance of the hole center from the bed boundaries (Ellis 1987). With rapid technological advancement, azimuthal GR tools have emerged and are now being used in the industry.

\section{Density and neutron porosity logs}

According to Singer (1992), the density tool is azimuthally focused which means that it reads density values in the direction in which it is focused. The neutron porosity tool, on the other hand, is effectively focused downward in horizontal wells because it lies at the bottom of the hole and the mud above slows down and absorbs the neutrons. Neutron tool reads deeper (12 in.) than the GR, and density reads shallower (6 in.) than the GR (Singer 1992). This phenomenon is very helpful in detecting the presence of another bed in the vicinity of the host bed. Typical responses of these tools are illustrated through cartoons in Fig. 1. In these illustrations, the tool moves from right to left, i.e., from the end of the hole toward the surface. In Fig. 1a, the sand approaches the tool from the top. Since both the neutron and the density tools have downward focus, they do not read the sand until they reach the sand-shale boundary. The GR tool, however, detects (moving from right to left) the sand bed before reaching the sand-shale boundary because it is not focused. The brown line shows the position of the GR tool and its reading. Upon entering the sand layer, all three tools detect the shale bed below from within the sand bed because neutron and density tools are focused downwards, i.e., in the direction of the shale layer. The neutron tool, which reads the deepest among the three, takes the longest time to settle to its final value toward the left (blue line), followed by the GR tool (green line) and the density tool (red line), respectively. It is notable that when in the sand bed, the GR tool ceases to detect the lower shale earlier than the neutron tool because the neutron tool reads deeper than the GR tool in the direction of focus (downwards).

In Fig. 1b, the tool approaches an underlying sand from an overlying shale. This time, the sand bed is detected first by the neutron tool that displays an upward-moving trend (i.e., decrease in absolute values in an inverted scale [broken blue line]) followed by the GR reading (broken brown line) that starts to move downwards, and the density tool whose reading decreases as well (broken green line). This phenomenon happens because both the neutron and GR tools are focused downward, combined with the fact that the neutron tool reads the deepest followed by the GR and the density tools, respectively. Upon crossing the sandshale boundary into the sand, the density and the neutron porosity readings do not change (broken red line) because they are focused downwards and do not record the shale signal from above. However, the GR tool, which has no azimuthal focus, still reads the upper shale from inside the

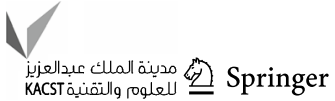




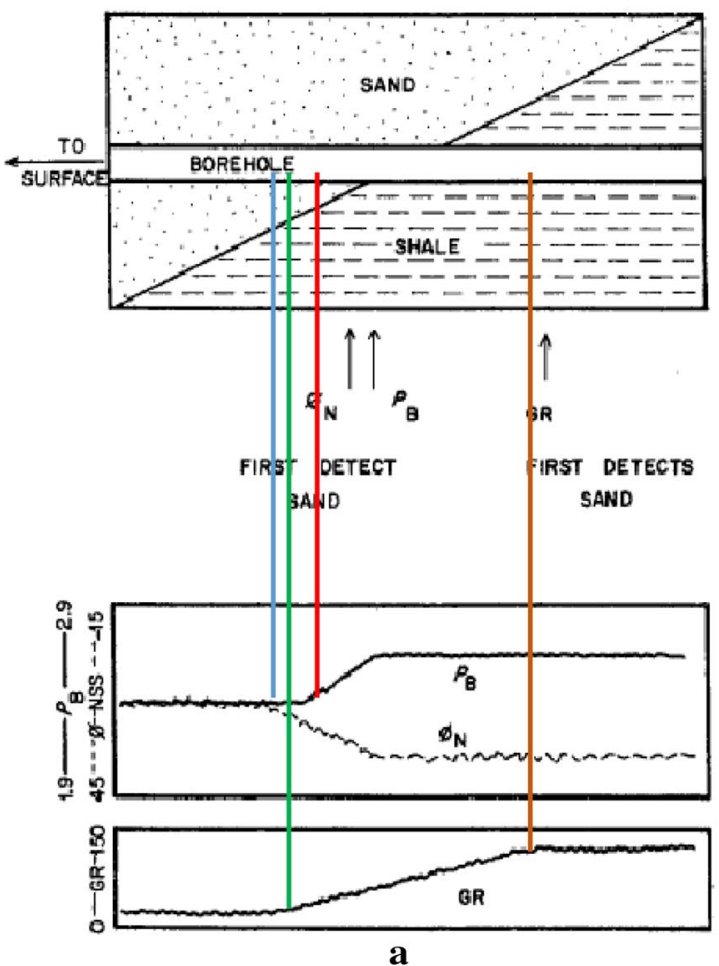

Fig. 1 Illustration of typical responses of the neutron porosity, density, and GR tools to detect the presence of a surrounding sand or shale bed. Note that the neutron and the density tools display sharper

sand bed. Therefore, by observing the delay in the reading changes of the three tools, the direction of an approaching bed can be determined.

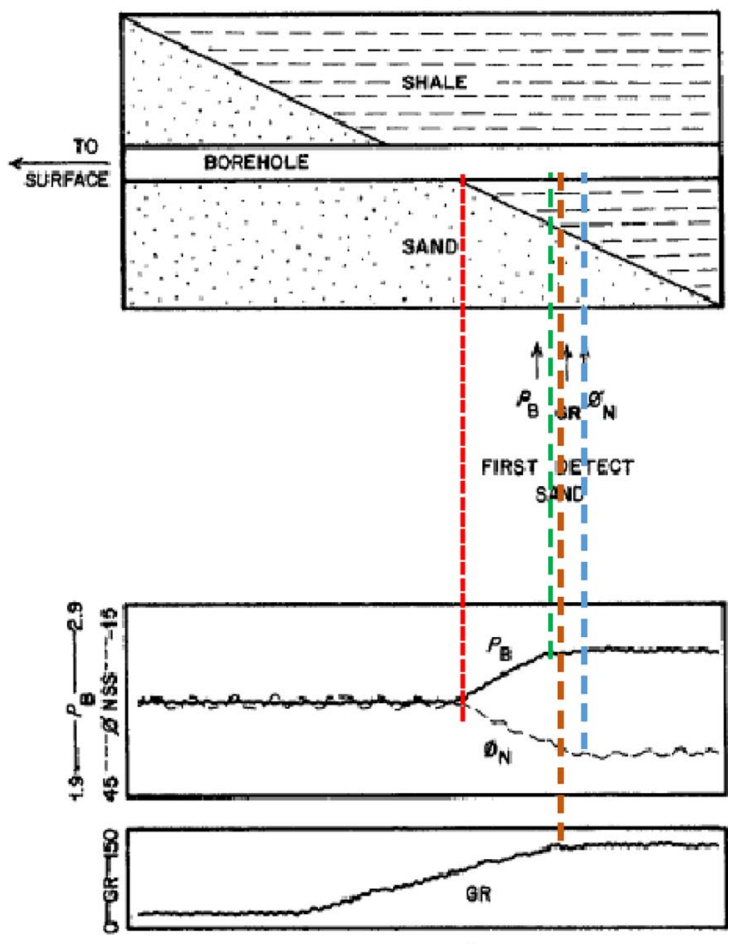

b

responses compared to the GR tool when crossing bed boundaries. The tool is moving from right to left in both $\mathbf{a}$ and $\mathbf{b}$. Figure modified from Singer (1992)

\section{Resistivity logs}

Deep induction $\log$ (ILd), medium induction log (ILm), and spherically focused $\log$ (SFL) do not have azimuthal focus. ILd and ILm depth of investigation depends on the resistivity level and resistivity contrast between the surrounding beds.
Fig. 2 Computed responses of the deep and medium induction tools at different distances from the bed boundaries. Figure modified from Singer (1992)

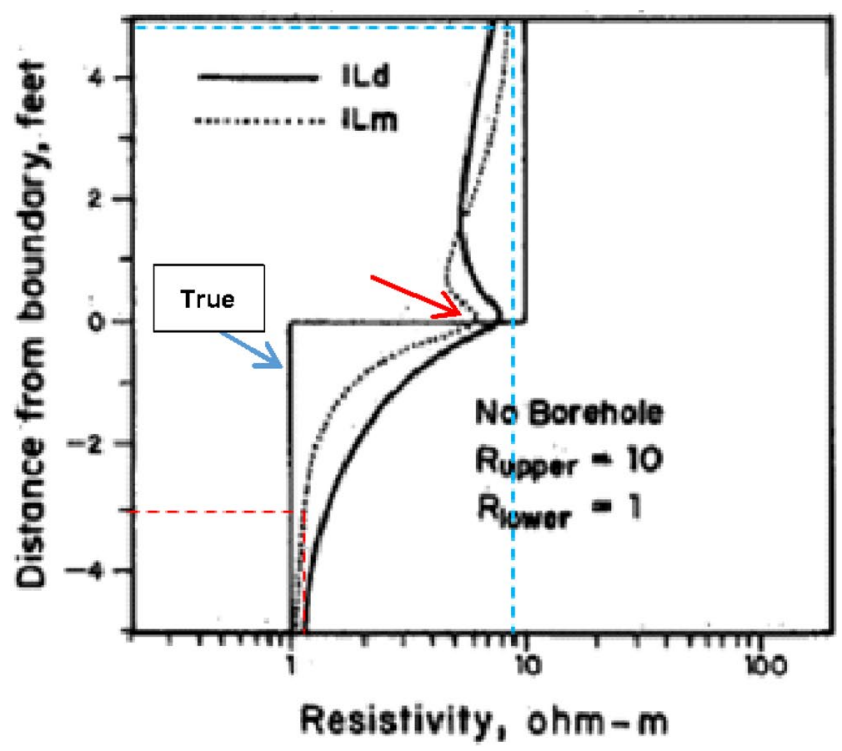


Also, a larger distance is required for the readings to reach their true values in resistive beds as compared to conductive beds (Singer 1992). In Fig. 2, the ILm tool reads nearly 1.05 $\Omega$-m within $3 \mathrm{ft}$ of the bed boundary, which is within $10 \%$ of the true resistivity ( $1 \Omega-\mathrm{m})$ of the lower conductive bed (dashed red). The broken blue line shows that in the upper resistive bed, whose true resistivity is $10 \Omega$-m, the ILm reads approximately $9 \Omega-\mathrm{m}$ beyond $5 \mathrm{ft}$ from the bed boundary, which is within $10 \%$ of the true value. The same reading error (10\%) for ILd is $5 \mathrm{ft}$ (compared to $3 \mathrm{ft}$ for ILm) and 7 $\mathrm{ft}$ (compared to $5 \mathrm{ft}$ for ILm), respectively (not shown in the figure). It is typical for both logs to show a spike (denoted by a red arrow) when crossing the bed boundaries as shown in Fig. 2.

Hagiwara (2006) mentioned that induction log tool response is a function of vertical and horizontal resistivities, tool configuration, and operating frequency. According to Zhou (2008), in LWD resistivity logs associated with horizontal and highly deviated wells "horns" are visible when the wellbore crosses a bed boundary. The size of the horn depends on the angle at which the wellbore intersects the beds. The tool response as a function of the apparent dip can be used to find geometric relationships.
Figure $3 \mathrm{a}$ shows idealized tool response in terms of induction log resistivity attenuation and phase. Attenuation refers to the reduction in the amplitude of an electromagnetic wave between two receivers ("attenuation resistivity," 2021). Phase shift is derived from the distance by which the peak positions of an electromagnetic wave changes between two receivers ("phase-shift resistivity," 2021). The model is that of a $10 \Omega$-m layer in a $1 \Omega$-m host. In this example, apparent dip is defined as the angle between the wellbore and normal to bedding. At $0^{\circ}$ apparent dip (i.e., wellbore oriented perpendicular to the bedding), there are no horns observed with either the resistivity phase shift (RP) curve in blue or the RA (resistivity attenuation) curve in magenta. In red, is the true resistivity curve. At a $70^{\circ}$ apparent dip, horns are very conspicuous in both the RP curve in blue and RA curve in red. At $85^{\circ}$ (i.e., wellbore almost parallel to the layers), both RA and RP horns move out of scale (denoted by a blue arrow). In other words, the horns become larger with a higher apparent dip (i.e., high parallelism between the well and bedding planes). In general, the curves are close at lower apparent dip and separate at larger dip angles as depicted in Fig. 3b (red arrow), which shows computed RP responses at different angles. There is not much separation between the horns up to a $60^{\circ}$ apparent dip angle (orange

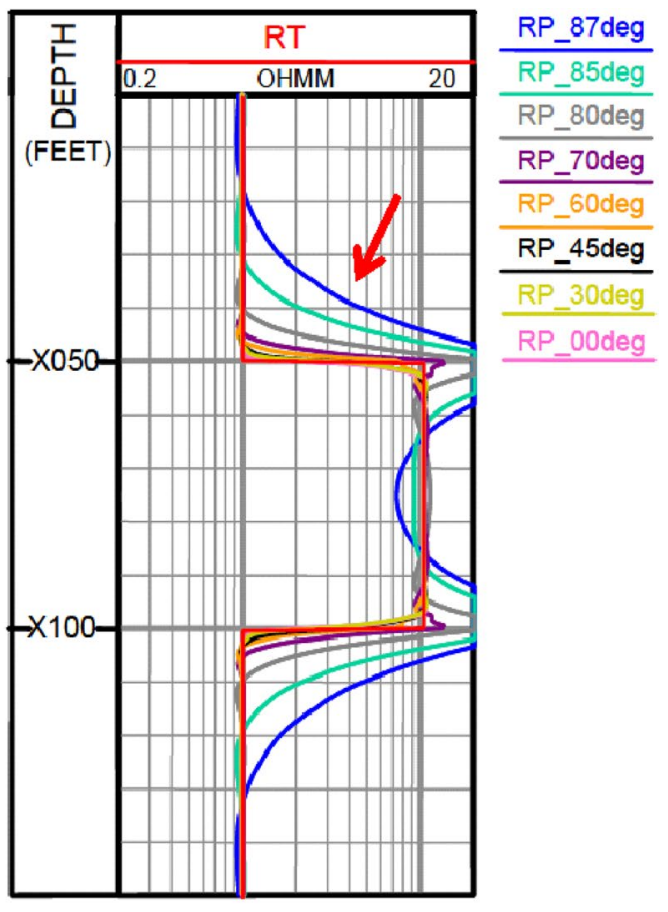

b
Fig. 3 a Comparison of RA and RP horns with apparent dip (angle between the wellbore and normal to bedding). Notice that the size of the horns increases with increasing parallelism (i.e., greater apparent dip angle) between the wellbore and bedding. b Comparison of RT horns at different apparent angles. With an increase in angle, the separation between each successive horn increases at a faster rate. Figure modified from Zhou (2008) 
curve). However, between $60^{\circ}$ and $70^{\circ}$ (purple), there is a considerable separation. Between $70^{\circ}$ and $80^{\circ}$, the difference is even larger and grows with a small change in angle. Horning of resistivity logs at lithological boundaries was also observed by Al-Khaldy et al. (2015) while drilling horizontal wells in a prolific Kuwait oil field.

\section{Nuclear magnetic resonance log}

In NMR tools, magnetization is applied to the hydrogen nuclei. T1 and T2 times of nuclei are used for determining pore size and type of fluid. While T1 corresponds to the buildup rate of longitudinal magnetization of the nuclei, T2 corresponds to the rate of transverse magnetization decay. Different cut-offs are applied on the incremental porosity versus $\mathrm{T} 2$ to determine the presence of capillary bound or free fluids. In sandstones, NMR response is free of lithology effects and is only affected by fluids (Pajchel et al. 2011). Therefore, it can be useful for positioning the well close to the hydrocarbon locations. It is also the only tool being used currently for ascertaining the presence of movable hydrocarbons (Pajchel et al. 2011). As discussed earlier, NMR logs are used with several other logs, such as resistivity and GR to quantify the lithology and the fluid content of the formation simultaneously.

\section{Pulsed neutron capture log}

Measurements from pulsed neutron capture (PNC) tools include total porosity (TPHI) and neutron capture cross sections $\left(\sum\right)$ of the formation and the borehole. Additionally, inelastic and capture GR count rates provide reservoir and borehole fluid information qualitatively. Generally, several up and down passes of the PNC tool are made, while the well is flowing and/or non-flowing. Sometimes, passes are also made while injecting seawater, crude oil, or borax water. The capture cross sections obtained during these passes can provide clues to the location of productive intervals outside the casing.

\section{Image logs}

Most observed natural fractures in the subsurface are vertical or dip at a high angle (e.g., Ghosh et al. 2018; Ghosh and Slatt 2019; Aghaei et al. 2020). Therefore, horizontal wells can sometimes intersect these fractures at high angles. These high angle intersections appear in the image logs as straight lines (Fig. 4a). The fractures (straight lines) appear horizontal and beds appear vertical if the logs are laid out vertically. These fractures can also appear as low amplitude sinusoids (Fig. 4b) if intersected at slightly oblique angles. Generally, closed (cemented) natural fractures can be better imaged using resistivity image logs (due to high resistivity contrast between fracture cement and surrounding rock), rather than acoustic logs (due to low impedance contrast between fracture cement and surrounding rock). This phenomenon can lead to undersampling of cemented natural fractures through sonic imagery. However, open (uncemented or induced) fractures or breakouts are well imaged by acoustic logs due to high contrast between the surrounding rock and fluid in the fracture (Gong et al. 2021). Craig et al. (2021) observed conductive induced hydraulic fractures along with resistive filled natural fracture in image logs.

The bedding planes can sometimes form interesting patterns such as Saddle (Fig. 4c) and Bull's eye (Fig. 4d) due to a combination of certain geologic conditions, combined with wellbore-bedding plane intersections at certain angles. Wellbore breakouts patterns caused by a combination of wellbore orientation with respect to the principal stress directions, principal stress anisotropy, and rock strength can be imaged by these logs. However, an early bird in the field of log interpretation can sometimes confound bedding planes and breakouts (Compare Figs. 4e and f). In these cases, caliper logs can help differentiate between the two, as caliper logs "see" breakouts with greater clarity. However, several factors, such as drilling conditions, rate of penetration, bit rotations per minute, and borehole geometry, can affect LWD acoustic imaging. Figure $4 \mathrm{f}$ shows artifacts resulting from changes in RPM during drilling. Therefore, one must know the drilling parameters while interpreting LWD image logs (Gong et al. 2021).

\section{Log data and log interpretation examples}

Sections 3.1-3.6 provide several examples of formation evaluation using logs from horizontal and highly deviated wells. These examples cover commonly obtained logs, such as GR, density, neutron, induction, resistivity (shallow to deep), as well as less common ones such as NMR and image logs. These examples are driven toward capturing a high-level view of the utility, advantages, and limitations of these logs. Table 1 provides a summary of observations made in examples 1-6 (Sects. 3.1-3.6). Skimming through the summary before diving into the details may provide greater clarity of thought to some readers. From the aforementioned discussion, it may be noted that in sufficiently thick formations and away from bed boundaries, logging tools will solely read the host bed properties as they do in vertical wells. Therefore, most observations in Table 1 are geared toward log readings in horizontal/deviated wells when tools are sufficiently close to bed boundaries, the host formations are thin, and the wellbore's environment is similar to those found in horizontal/ deviated wells. In the table, "azimuthal" refers to tools that can be focused in one desired direction and read formation signals from that single direction. "Non-azimuthal" refers 

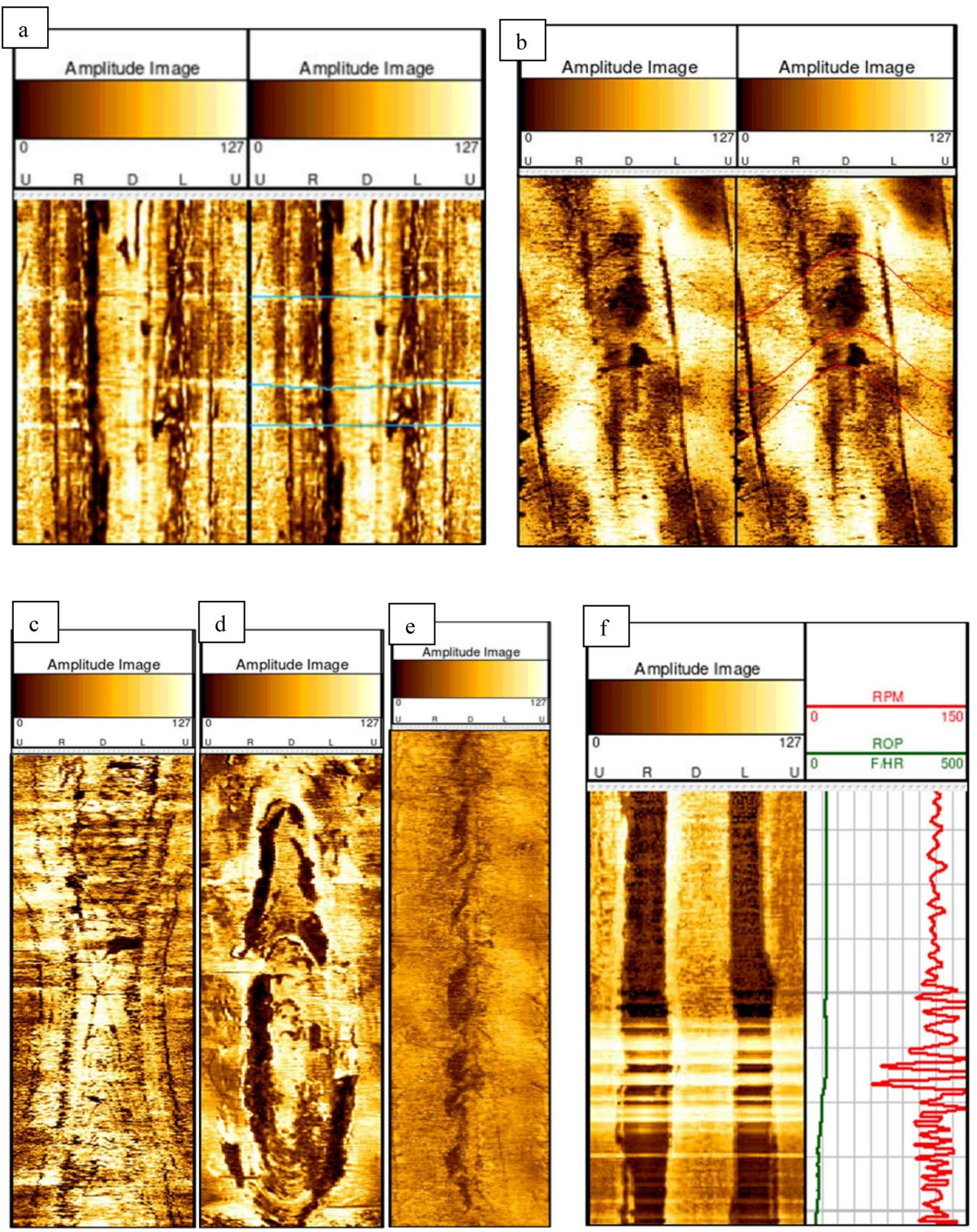

Fig. 4 Examples of image log interpretation in horizontal wells. a Dark vertical lines are bedding planes. Fractures are highly dipping and intersecting a near-horizontal well almost perpendicularly, resulting in straight lines. b Dark vertical lines are probable bed boundaries. Wellbore is intersecting highly dipping fractures at slightly lower than $90^{\circ}$ angle, resulting in sinusoids. Note: in both a and b, the first (left) picture is uninterpreted and the second image has fractures marked. c Saddle pattern and d Bull's eye pattern. e Breakout at the bottom of horizontal well along (parallel) the wellbore axis. f High contrast light and dark beds (vertical structures) interrupted by drilling-related artifacts. Images were obtained from Gong et al. (2021) 
to tools that cannot be focused and thus, respond to signals from all directions.

\section{Example 1}

Figure 5 shows wells logs from a horizontal well. The target formation is a $40 \mathrm{ft}$ thick sand. The well, however, was not drilled entirely in the sand because much of the sand was missed unintentionally due to the absence of GR and resistivity measurements during drilling. Between the depths of 7380 and $7550 \mathrm{ft}$, GR has high values, suggesting the well is in a shale layer. The SFL reads the lowest (solid red line) among the three resistivities, i.e., that of the host shale. At this depth, the ILD reads the highest (solid green line), i.e., that of the neighboring sand.

From 7280 to $7350 \mathrm{ft}$, the well is in the target sand layer indicated by the low GR reading. In this layer, the SFL shows the highest value (broken red line) followed by the ILM and ILD. Again, the adjacent shale has a large effect on the ILD (lower values compared to ILM and SFL), while SFL has the high value, i.e., that of the host sand. In addition, the ILD and ILM show peaks when crossing bed boundaries, i.e., at depths of nearly 7780 and $7790 \mathrm{ft}$ (indicated by solid blue arrows). Just below $7760 \mathrm{ft}$, when the well is still in the sand, the SFL starts to show a very low reading (broken black arrow), suggesting that the shale boundary is very close, probably within $1 \mathrm{ft}$ (Singer 1992).

Near $7375 \mathrm{ft}$, the neutron tool shows a sharp response (broken orange arrow toward the right). Between 7375 and $7354 \mathrm{ft}$, GR shows a slow response (broken orange arrow toward the left), which is typical for a GR $\log$ as shown in Fig. 1. It is important to note that going from high to low TVD between 7375 and $7345 \mathrm{ft}$, the neutron and the GR value start to change almost simultaneously (at higher TVD), but toward the lower TVD (shallower depth), GR value is still decreasing when the neutron porosity value has already settled (dashed red line). This trend is shown in Fig. 1b earlier. This behavior suggests that the sand is approaching from the bottom at this depth range.

Sharp changes in the GR pattern values are evident between the depths of 7760 and $7850 \mathrm{ft}$ (thick red broken arrows). According to Singer (1992), these observations are likely caused by faults, and not by lateral changes in lithology due to a layer gradually approaching the wellbore. The low subsequent production rate from the 40-ft-thick sand (thick broken blue line) also supports the speculation that these faults have disconnected the sand.

\section{Example 2}

This is an example showing RP and RA log interpretation in a horizontal well. Figure 6 shows several different LWD measurements in a horizontal well. In the top row 


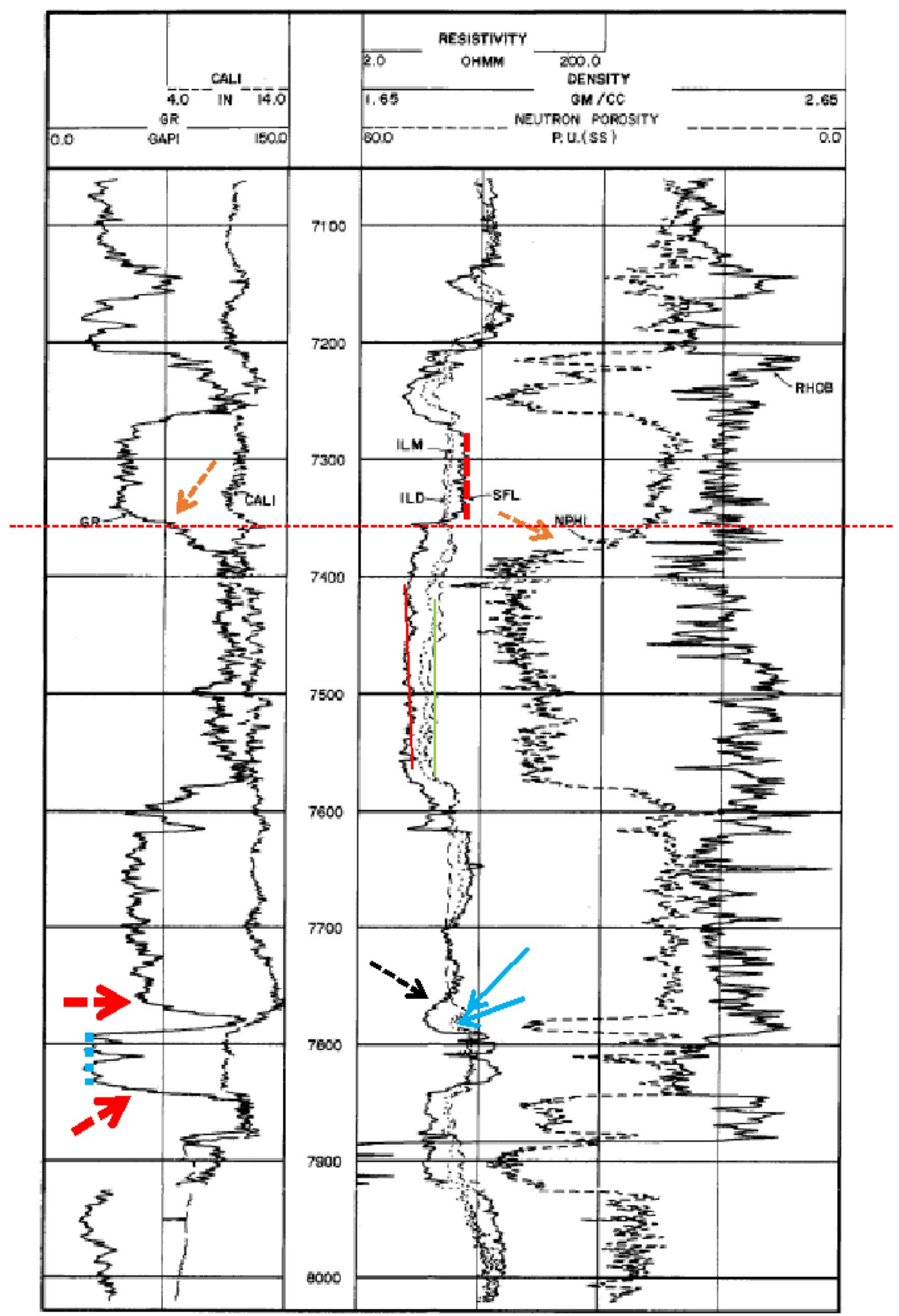

Fig. 5 GR, caliper, ILM, ILD, SFL, density, and neutron porosity (NPHI) logs recorded in a horizontal well. Figure modified from Singer (1992) 


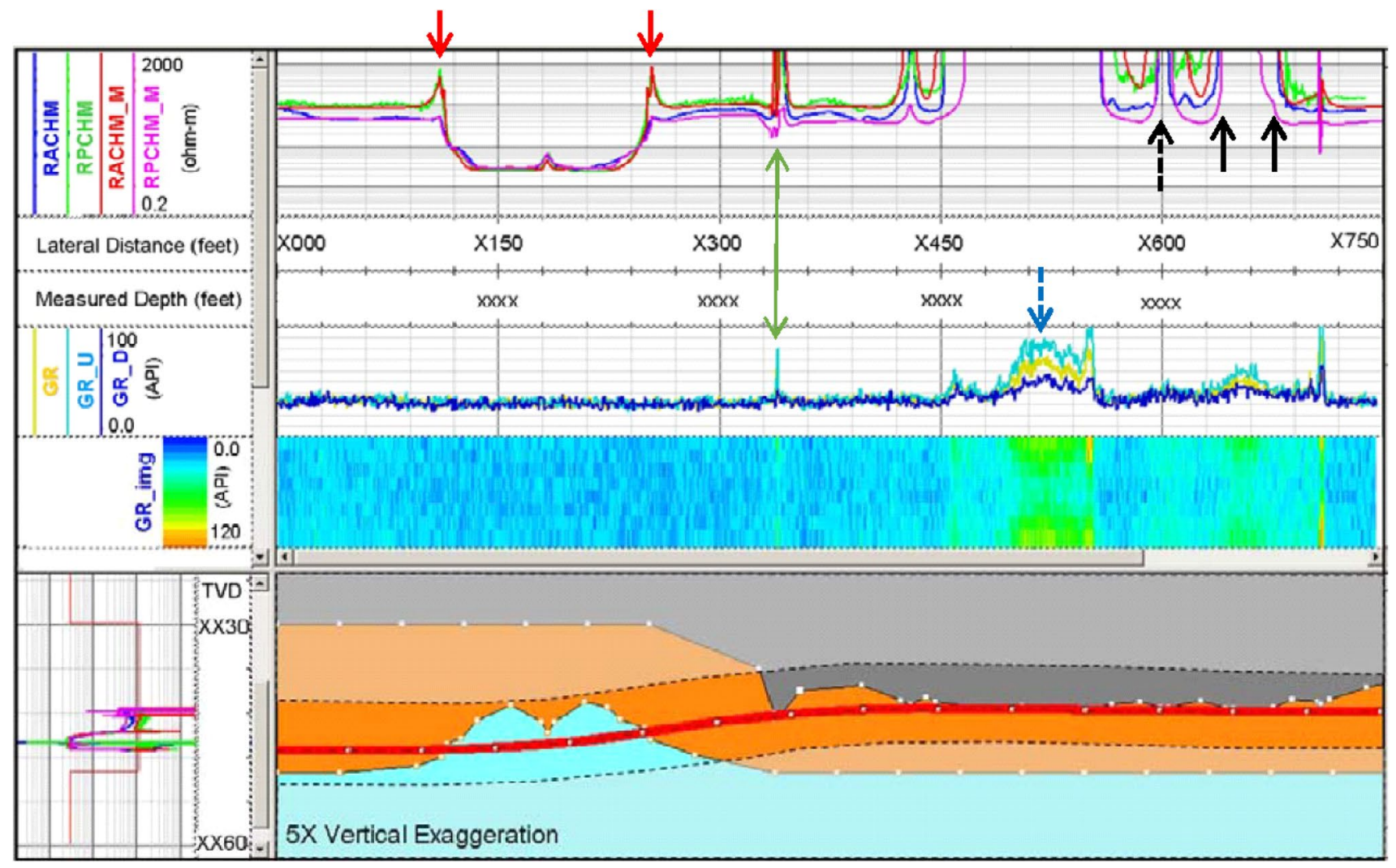

Fig. 6 Measured resistivity attenuation and phase (RACHM, RPCHM), modeled resistivity attenuation and phase (RACHM_M, RPCHM_M) logs are shown in the top horizontal track. Also shown are the average, upward-focused, and downward-focused gamma ray

(first track at the top), RACHM, RPCHM, RACHM_M, and RPCHM_M are the measured attenuation, measured phase shift, modeled attenuation, and modeled phase shift, respectively. In the track showing the GR reading, there are three values GR_U, GR_D, and GR, which are up-sensing GR, down-sensing GR, and the average of the two, respectively. Note that, unlike the earlier example, in which the GR was not focused azimuthally, in this example, the GR is focused in the upward and the downward directions. Between X000 and $\mathrm{X} 340 \mathrm{ft}$, the GR reading is low indicating that the well is well within the sand. But the resistivity logs between X110 and $\mathrm{X} 250 \mathrm{ft}$ (solid red arrows pointing down) show a sudden drop, which according to Zhou (2008), may be a result of water coning because the field has been under production and water flooding for many years. There are upward spikes (horns) in the RPCHM and RACHM values at the edges of the water cone (at the red arrows pointing down). This is a common observation for both phase- and attenuation resistivities in highly deviated and horizontal wells, as is shown in Fig. 3.

Near X340 ft, there is another spike (double-sided solid green arrow) in GR_U but not GR_D, indicating the roof
(GR, GR_U, GR_D) logs and the interpreted cross section of the reservoir (bottom of the figure) using the logs. Figure modified from Zhou (2008)

shale has come in contact with the borehole locally. At this depth, there is also a spike in the resistivity amplitude and phase, supporting this observation (double-sided solid green arrow). Near depths between X450 and X560 ft, the resistivity logs shoot out of range. The GR_U at this depth range shows a large value that is higher than the GR_D (broken blue arrow pointing down), indicating that the wellbore is barely in the shale (Zhou 2008). Similarly, the GR and resistivity values show that the well touches the shale near X600 ft (broken black arrow) and between X640 and X670 ft (solid black arrows). At the bottom of Fig. 6 is an illustration of the estimated reservoir structure with the wellbore marked in red. It is an estimation because the logs are not sensitive to rocks too far from the wellbore. Water coning and the wellbore touching the overlying shale at several points is observed in the illustration.

\section{Example 3}

This example shows the dip effect correction of resistivity $\log s$ and bed dip magnitude determination in highly deviated wells. In Fig. 7, the borehole dip is about $60^{\circ}$. 


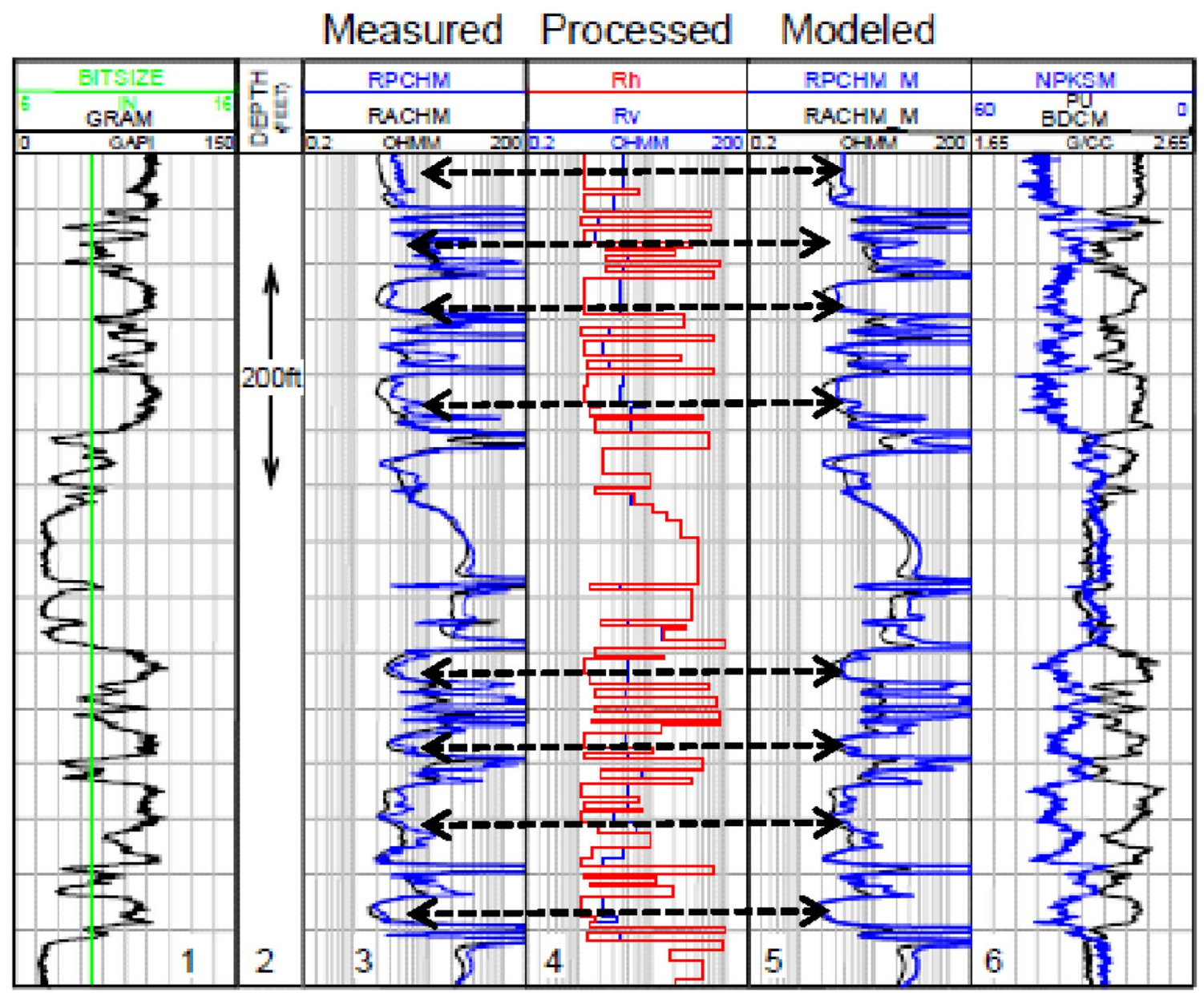

Fig. 7 Resistivity log correction and bed dip determination. Track 1 shows GR; Track 3 shows resistivity phase (RP) and resistivity attenuation (RA); Track 4 shows the modeled true vertical and horizontal resistivities $(\mathrm{Rv}, \mathrm{Rh})$ calculated using the data from Track 3; Track

Track 3 shows the measured RP (blue) and RA (black). As expected, there are large resistive horns because of the large apparent dip, and therefore, the values cannot be used directly in the measurement of fluid saturation (Zhou 2008). The severity of horns also indicates that the apparent dip (angle between the borehole and rock layers) is greater than $60^{\circ}$, i.e., the rock layers are not horizontal. Modeling/inversion was performed to find the true resistivities. In this case, by modeling the LWD tool response, the best fit was found at $75^{\circ}$ apparent dip. The modeling/ inversion process is not discussed here. Track 4 shows the processed true resistivity (i.e., as if the angle between beds and well is $90^{\circ}$ ) values in both horizontal (Rh-in red) and vertical ( $\mathrm{Rv}$-in blue) directions. In the shale layers (high GR), there is clearly larger anisotropy indicated by the large separation between the red and blue lines in Track 4 (double-sided broken black arrows). Track 5 shows the modeled RP and RA (i.e., RPCHM_M and RACHM_M)
5 shows the modeled RP and RA values obtained by using the true resistivity values in Track 4. Note the similarity between RP and RA curve trends in Tracks 3 and 5. Figure modified from Zhou (2008)

values if the logging tool were run through a formation with the log values in Track 4 . This process is similar to a convolution of calculated (processed) values with the tool response. There is a remarkable similarity between the curves in Track 5 and measured values in Track 3, indicating that the values in Track 4 are reasonably close to the true resistivity values. The bed dip was found to be $15^{\circ}$, which is the difference between the apparent dip of $75^{\circ}$ and the borehole inclination of $60^{\circ}$ (Zhou 2008).

\section{Example 4}

This is a log processing workflow example from Griffiths et al. (2012) of the "model-compare-update" method in horizontal wells in the North Sea. Figure 8 shows the workflow.

The task was to place a horizontal/high angle well in a thin $(13 \mathrm{ft})$ reservoir sand. Figure 9 shows the measured values from the well. Measured data consist of a density

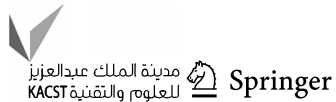




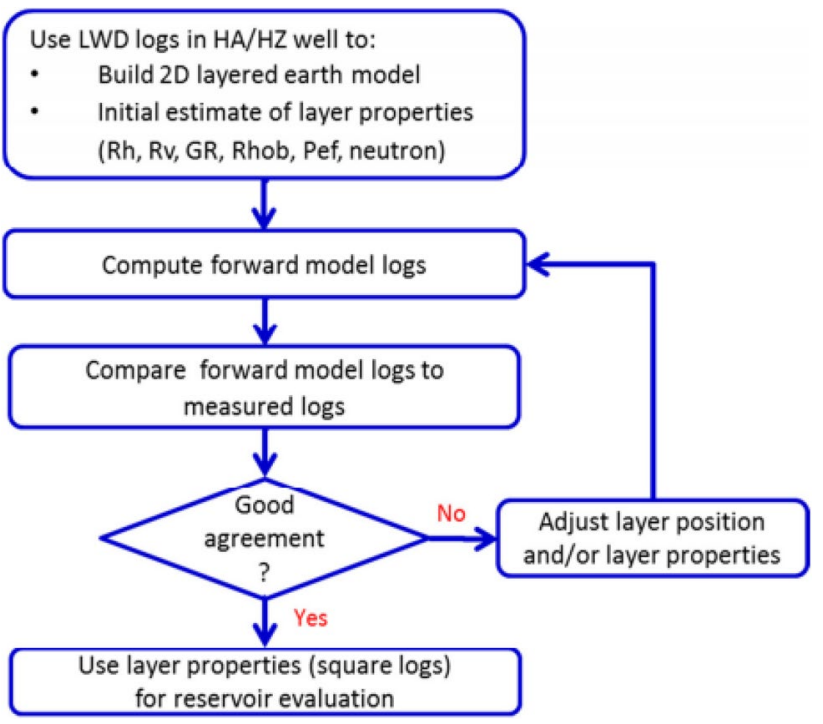

Fig. 8 Model-compare-update method workflow. Figure from Griffiths et al. (2012) image, attenuation and phase resistivities, and GR. The well trajectory (black line) is also shown at the bottom panel. Bed boundaries and their apparent dips visible in the density image logs are marked (as dipsticks in blue) on the trajectory image. Dipstick directions indicate the bedding orientations at the bed boundaries. Vertical lines (black) connect the log positions to the dipsticks.

Figure 10 depicts the stratigraphy after several iterations run using the "model-compare-update" method. Griffiths et al. (2012) tried to match the boundary positions and the measured log values simultaneously. They tried to obtain the simplest possible geological/petrophysical model that satisfied the observed situation, even though a complex model could better match the observed values. Figure 10 shows that both boundary positions and modeled logs are consistent. The overlying shale has low resistivity (indicated by "1" on the resistivity $\log$ ). The underlying sand resistivity (indicated by "2") is lower compared to the main reservoir sand due to possible waterflooding. The GR response was matched accurately, placing the model close to the ground reality. The resistivity matching was somewhat difficult due

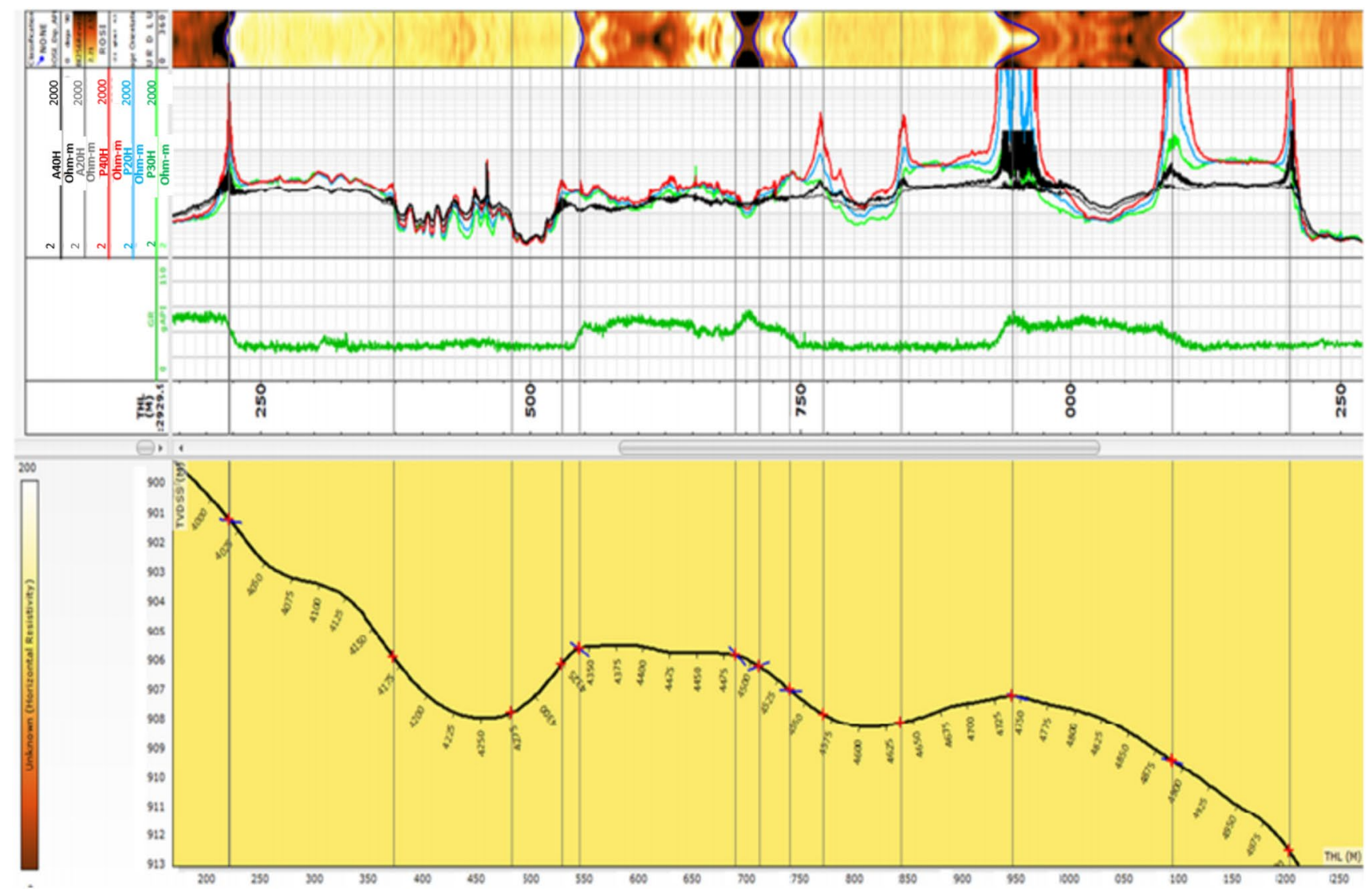

Fig. 9 Well logs (density image, resistivity, GR [top to bottom]) and corresponding envisioned well trajectory. Features on the density image log coincide with those in the GR log. Blue markers in the well trajectory panel indicate bed dips at formation boundaries as observed from the well. Marker positions were aided by density image/GR and resistivity logs. Figure obtained from Griffiths et al. (2012) 


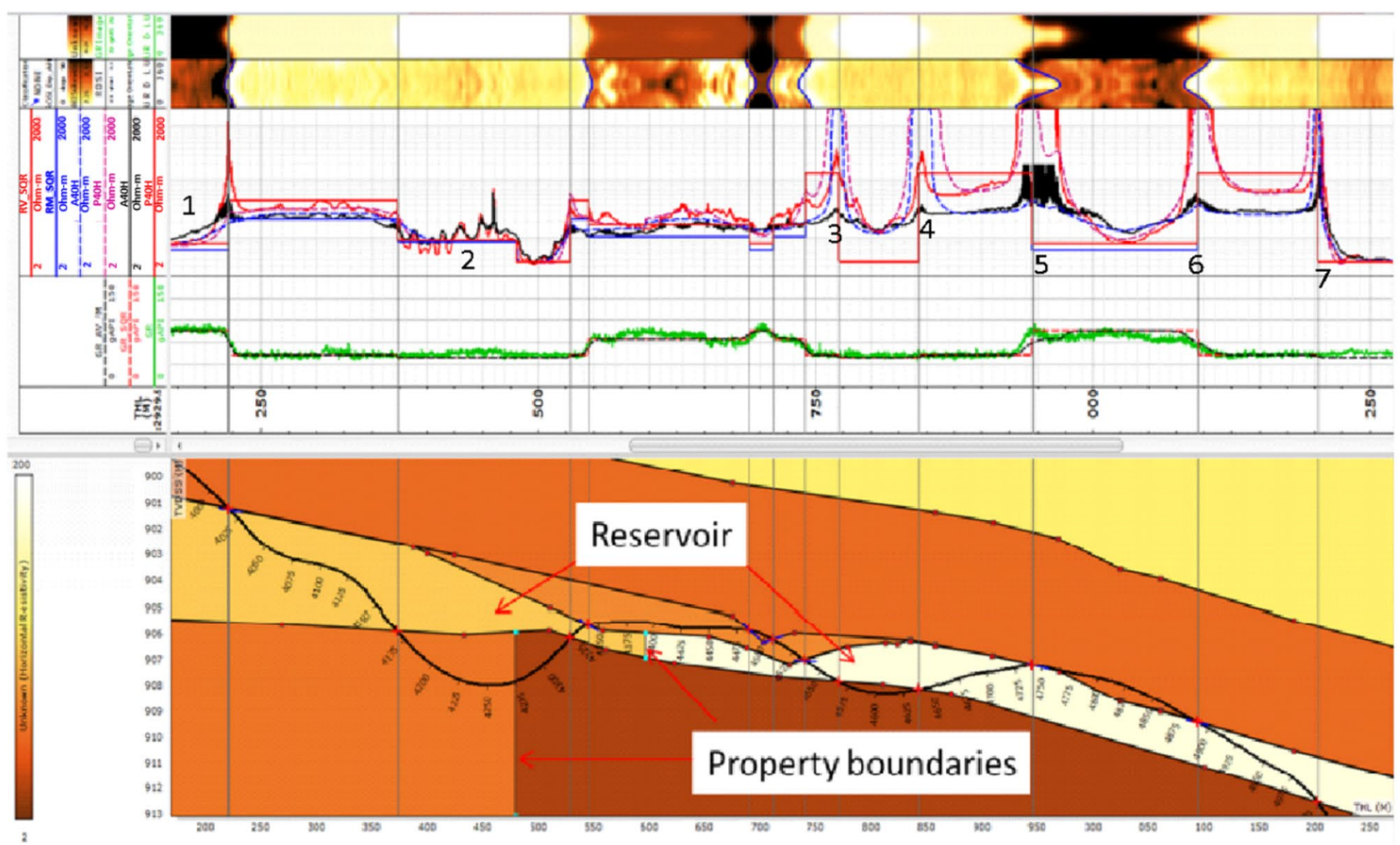

Fig. 10 Geologic/petrophysical model obtained after copious iterations of the model-compare-update workflow. Figure obtained from Griffiths et al. (2012)

to the presence of large horns. Some of these horns do not coincide with GR perturbation ("3", "4", "7" at sand-sand boundaries), while others do ("5", "6" at sand-shale boundaries). To match the resistivities, a single resistivity value for each layer was not sufficient. Therefore, resistivity boundaries were introduced for both the reservoir sand layer and the layer below the reservoir. Resistivity values are different on either side of the boundaries. It is noteworthy that the modeled resistivities lack the horns observed in the measured resistivities. Resistivity horns can lead to erroneous water saturation calculations in horizontal and highly deviated wells.

\section{Example 5}

This is an example of a NMR and resistivity log interpretation in a horizontal well. Figure 11 shows the trajectory of a horizontal well drilled in the North Sea. This is a mature field and has been waterflooded for enhanced oil recovery. The target formation is the upper Fensfjord Sandstone, which is composed of fine-grained mica, K-feldspar, and glauconite-rich quartz. While the completed part of the upper Fensfjord (3300-3720 m) contains hydrocarbons, the other part (3954-4400 m) of the upper Fensfjord does not contain hydrocarbons in commercial quantities. Pajchel et al. (2011) do not provide the T2 response data in the completed (producing) zone, but provide it for depths between 4330 and $4500 \mathrm{~m}$, which is within the hydrocarbon-poor zone of the upper Fensfjord. The heel and toe of the well intersect the heather formation. The lower part of the Heather is micaceous or calcareous silty claystone. The middle Fensfjord consists of shale and silt deposits.

Figure 12 shows the $\log$ s between 4330 and $4400 \mathrm{~m}$. The NMR tool being used measures T2 and not T1. The T2 geometric mean for oil was determined to be approximately $900 \mathrm{~ms}$, and the minimum T2 for the movable oil was approximately $250 \mathrm{~ms}$ (Pajchel et al. 2011). The range for T2 distribution values shown in the graph is between 0.5-4096 ms. The Fensfjord formation typically has a low resistivity response due to partial water flooding. In the bed being considered, the LWD resistivity measurements are known to be frequently affected by shoulder beds or the proximity of calcite.

Notice that in the "Resistivity and Perm" track, the resistivity values (brown, green, pink, and black curves) track each other in the zone below the lower red arrow. Between the two red arrows (4330-4400 m), resistivity increases bottom to top. However, the T2 spectrum (between black arrows) in the same interval does not indicate a significant increase in oil saturation. At about $1000 \mathrm{~ms}$, shown 


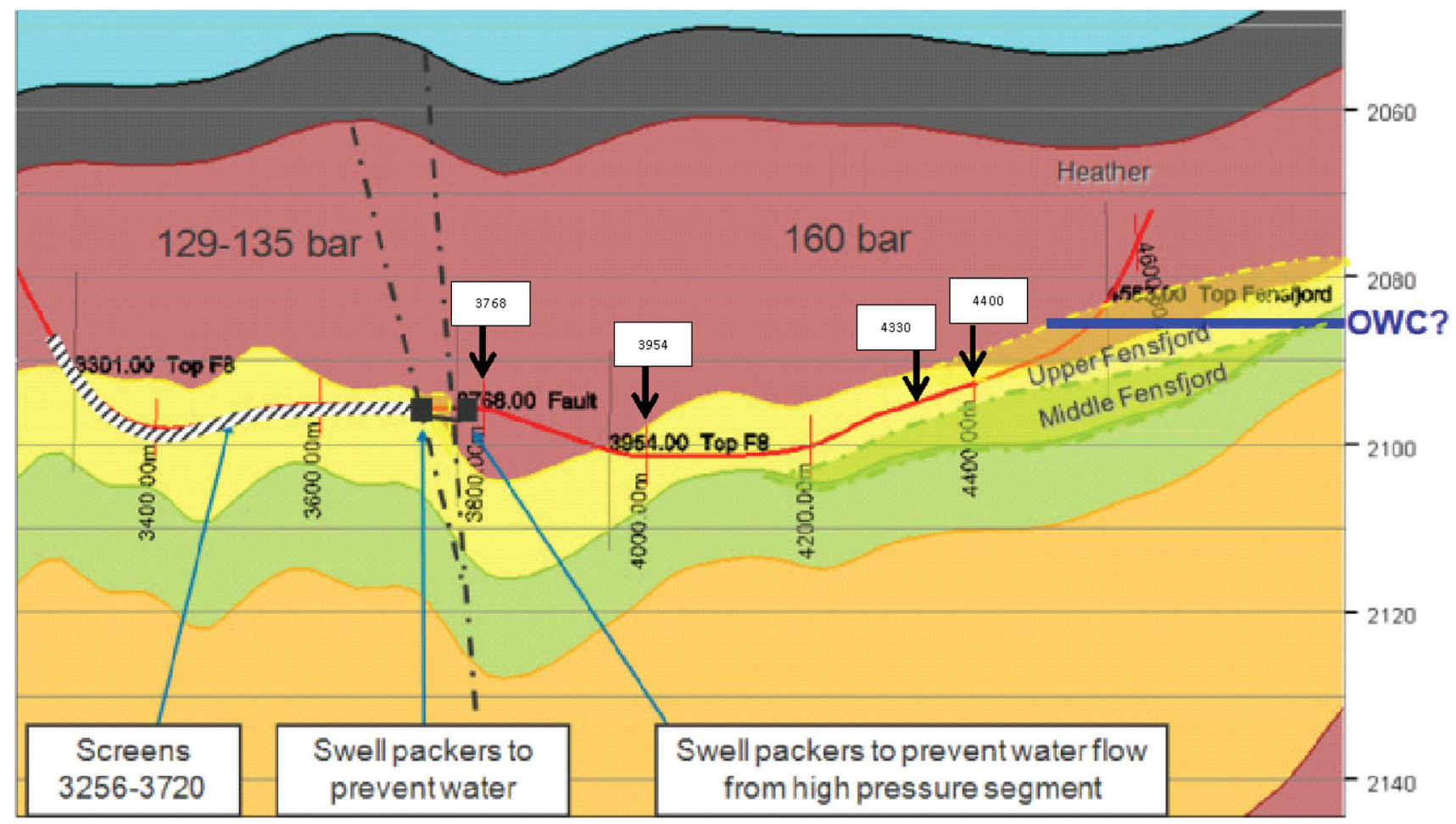

Fig. 11 Horizontal well trajectory in a field located in the North Sea. Figure modified from Pajchel et al. (2011)

using a downward-pointing broken red arrow $(900 \mathrm{~ms}$ is the peak for oil), there is no significant peak height (green and blue spots [no red]) in the entire section. All the high peaks (red) between 10 and $100 \mathrm{~ms}$ probably represent free water brought in by water flooding conducted previously. In fact, the $\mathrm{T} 2$ values do not show any considerable change in the entire section presented in the log. According to Pajchel et al. (2011), the high resistivity values (4330-4400 m) come from shoulder effects and provide a wrong hydrocarbon indication. In Fig. 11, the wellbore comes within 2-3 $\mathrm{m}$ of the lower Heather formation and the upper part of the Middle Fensfjord formation at depths between 4330 and $4400 \mathrm{~m}$, affecting the resistivity curves, which read deeper than NMR. The author does not discuss the lower neutron porosity and higher bulk density at the high resistivity zone. Another confirmation for the lack of hydrocarbons between 4330 and $4400 \mathrm{~m}$ is that at $3768 \mathrm{~m}$ there is a fault, and pore pressures are different on each side of the fault. This observation shows that the oil in the completed part of the Upper Fensfjord is not connected to the water-saturated part on the right side of the fault.

\section{Example 6}

This is an example of PNC log interpretation in a horizontal well. The well is located in the Alaskan North Slope and has a cemented and perforated completion. It produces approximately 1350 BOPD with a GOR of 13,500 and no water. Since the North Slope brine has low salinity, there is not much resistivity contrast between the formation water and liquid hydrocarbons. Therefore, the tool response mainly depicts the lithology contrast. The authors (Brady et al. 1996, 1998) have used the words "permeability" and "productivity" interchangeably in their papers while discussing the same diagram, which is shown in Fig. 13.

Track 1 shows the GR reading and the perforated intervals. Track 2 shows the well trajectory and hole deviation at different depths. Track 3 shows the overlay of neutron capture cross section while injecting seawater $\left(\sum\right.$ psw) and borax water $\left(\sum \mathrm{pbw}\right)$. The values in the track increase from right to left. The increase in the $\sum$ pbw value (curve moving toward left) indicates areas where the borax water was placed in the formation, indicating permeable and productive zones (Brady et al. 1996, 1998). According to Brady et al. (1996) and Brady et al. (1998), more permeable and productive formations have moderate to low $\sum$ psw values (indicated by the curve moving toward the right). These layers marked by large separation between $\sum$ psw and $\sum$ pbw are shaded in black and also shown by double-sided broken green arrows. Track 4 shows an overlay of $\sum$ psw and TPHI curves. Here, the $\sum$ psw is the same as in Track 3 and the TPHI curve moves toward the left (i.e., toward higher values) in high porous/permeable zones. Therefore, in Track 
Fig. 12 GR, caliper, resistivity, porosity, and NMR T2 distribution for a horizontal well drilled in the North Sea. Notice that there is no significant change in the $\mathrm{T} 2$ distribution between 4330 and $4400 \mathrm{~m}$ where the resistivity values are much higher compared to the deeper zone. Modified from Pajchel et al. (2011)

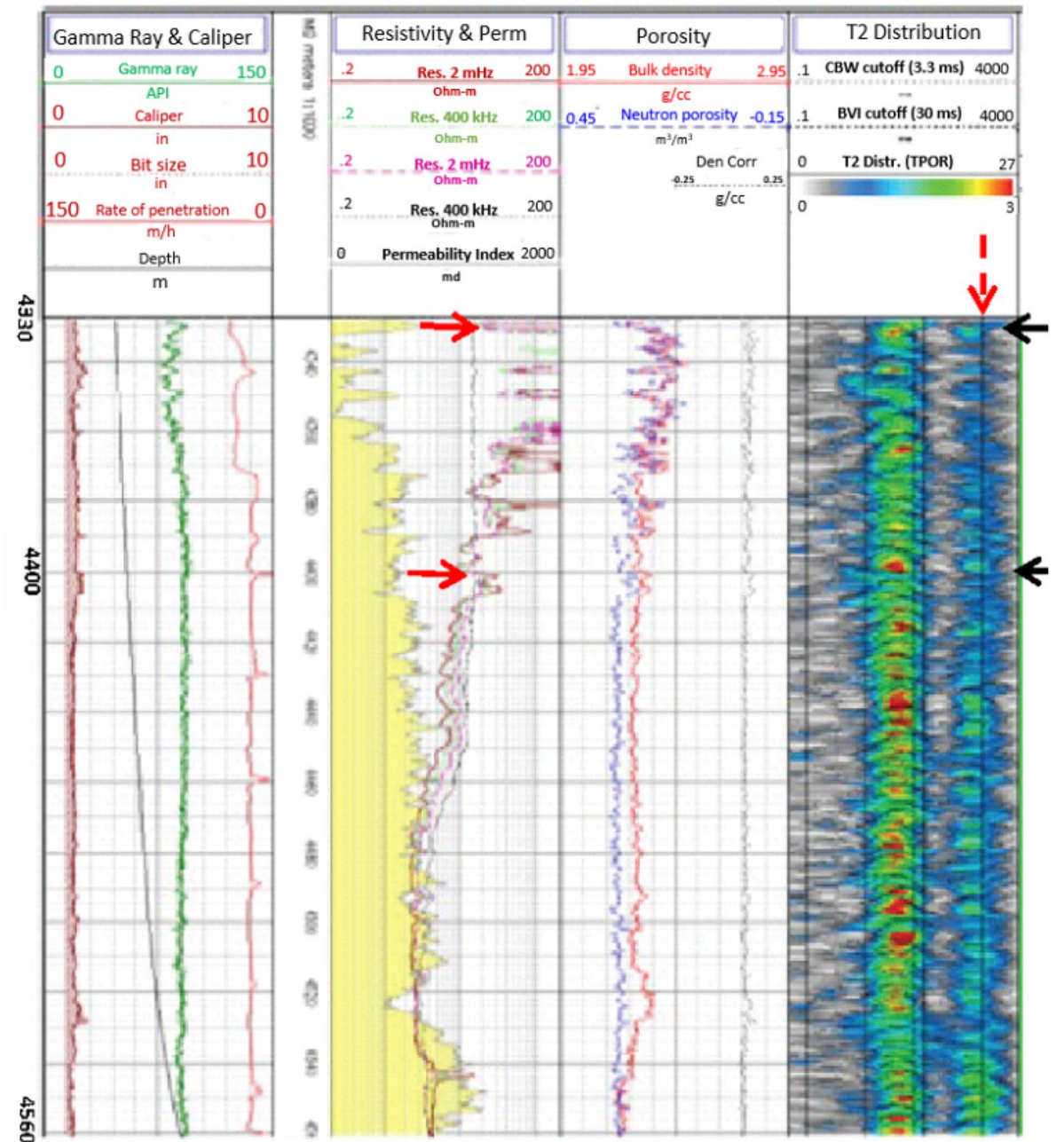

4, there is a separation between $\sum$ psw and TPHI in more permeable and productive formations, which is shaded in black (also indicated by double-sided broken green arrows). There is a remarkable similarity in the shaded regions in Tracks 3 and 4. One advantage of using $\sum$ psw and TPHI overlay is that borax injection is not needed and therefore, can identify potentially productive zones that have not been perforated (Brady et al. 1998). Low permeability formations, such as shales, have much lower separation shown by red bars. Yellow bars show depths with overall low GR (indicating lowshale content) where $\sum$ psw and $\sum$ pbw overlay shows lower values compared to $\sum$ psw and TPHI overlay. Among other explanations, this may be an indication of potentially productive zones that have not yet been perforated.

\section{Path forward}

Several authors have proposed methods for forward modeling (i.e., matching of recorded and calculated logs) as mentioned earlier. In their usage of deviated and horizontal well logs, geological modeling and bed geometry issues have been adequately addressed. Therefore, the present methods are satisfactory for defining stratigraphy/structure, not only when the wells are within the reservoir, but also when they are close to the non-reservoir rock or crisscross layers at multiple points. The existing methods also seem to provide sufficiently accurate qualitative information about the reservoir. However, any investigator is yet to establish the validity of their models for quantitative petrophysical interpretation through laboratory or field studies. More attention should be diverted toward developing a workflow for using these logs in quantitatively determining net to gross, porosity, and saturation (water, oil, and gas). Additionally, determining the spatial and temporal variabilities of oil-water or gasoil contacts using horizontal and highly deviated well logs should be given priority for future research. Incorporating these considerations will help in the estimation of original hydrocarbons in place, especially in the absence of nearby vertical wells (e.g., extended-reach wells for offshore formations drilled from onshore). In the case of mature fields, estimation of remaining hydrocarbons in place using horizontal

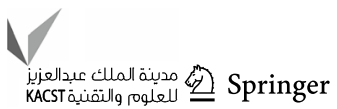




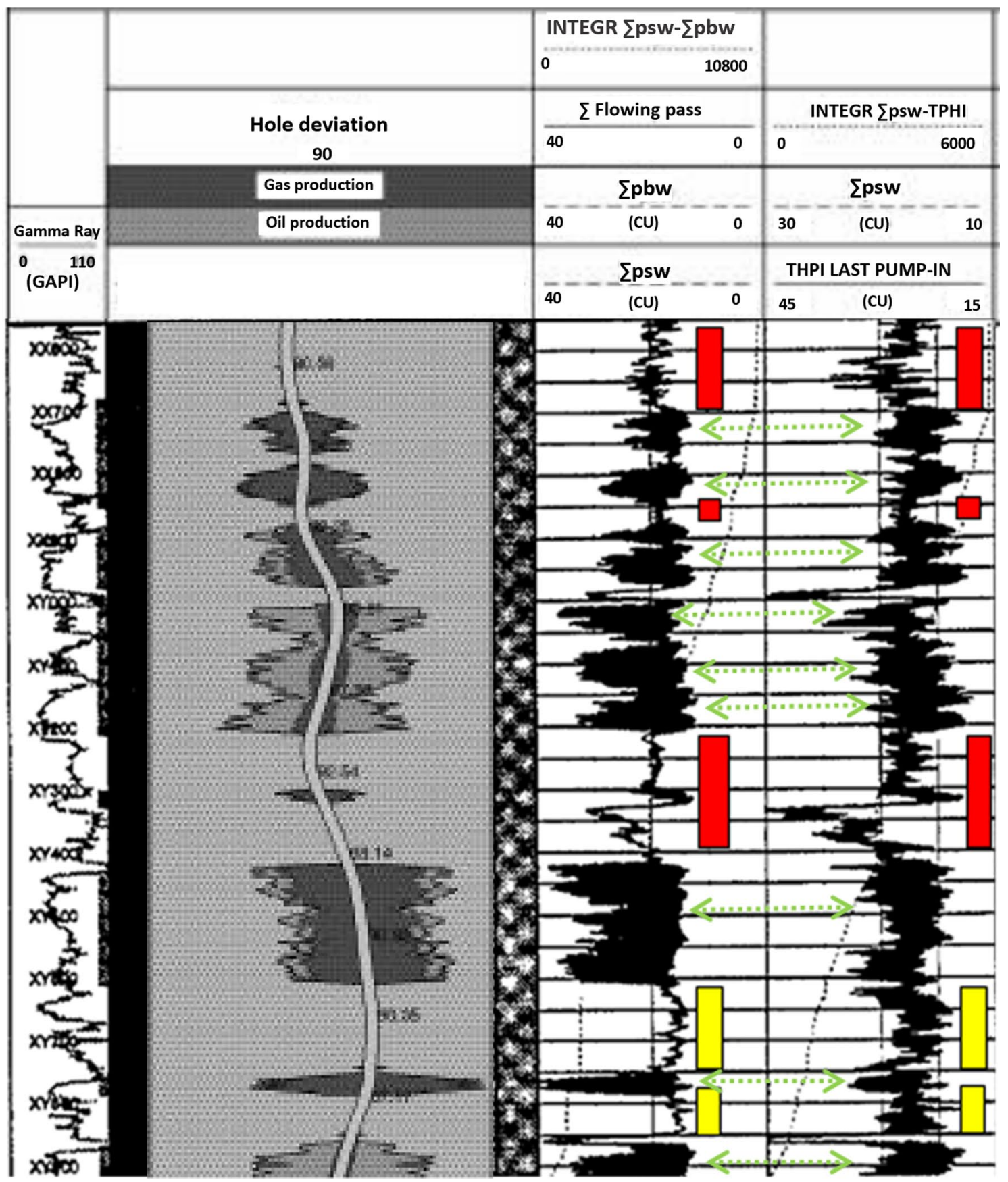

Fig. 13 GR and perforated intervals are shown on the leftmost track. Track 2 shows the hole trajectory and deviation which is very close to $90^{\circ}$ (i.e., horizontal). Note that in the shaded areas (indicated by double-sided green arrows) of $\sum$ pbw and $\sum$ psw overlay, the curve to the left is $\sum$ pbw and that to the right is $\sum$ psw. Similarly, for the $\sum$ psw and TPHI overlay, the curve to the left is TPHI and that to the right is $\sum$ psw. Red bars indicate layers of low porosity and permeability/ productivity. The green arrows show zones that have been perforated and have higher permeability/productivity. Zones shown by the yellow bars are unperforated and probably productive. Figure modified from Brady et al. (1998)

the development of new tool designs and methods that can address these issues of quantitative interpretation in horizontal and highly deviated wells. tiary field development planning. Such decisions may lead to early field abandonment (if hydrocarbons are absent in commercial quantities) or secondary/tertiary field development pursuits. Therefore, further research should prioritize 


\section{Conclusions}

This work covers the usage of major logging tools in highly deviated settings. It was shown that the relative change in GR reading compared to density and neutron $\log$ can identify the direction of approaching beds. It was demonstrated that comparison between the deep, medium, and shallow resistivity $\operatorname{logs}$ in a single run can help detect the beds nearby. Image logs were found to be useful in delineating the horizontal well-bed boundaries and natural fractures, both of which would be otherwise ambiguous. NMR T2 readings were shown to reveal if the high resistivity values obtained from resistivity logs are a result of hydrocarbon presence or the influence of surrounding beds. Additionally, pulsed neutron logs were shown to identify potentially productive unperforated zones. Finally, it was demonstrated that inversion can extract usable data from resistivity logs. Most importantly, inversion was shown to aid in the attainment of an accurate geologic model, while respecting the petrophysical properties. Given, so many positive aspects of formation evaluation in horizontal wells, the need for research on the quantitative aspects remains.

Acknowledgements Sincere thanks to SPWLA and SPE for allowing inclusion of various illustrations in this work. Also, thanks to the University of Oklahoma (Norman) and University of Petroleum and Energy Studies (Dehradun) for facilitating this work.

Author's contributions All work was performed by the sole author (Sayantan Ghosh).

Funding No funding was received for conducting this study.

Data availability and materials Data sources analyzed during this study are mentioned in the text itself.

\section{Declarations}

Conflict of interest The authors declare that they have no competing interests.

Open Access This article is licensed under a Creative Commons Attribution 4.0 International License, which permits use, sharing, adaptation, distribution and reproduction in any medium or format, as long as you give appropriate credit to the original author(s) and the source, provide a link to the Creative Commons licence, and indicate if changes were made. The images or other third party material in this article are included in the article's Creative Commons licence, unless indicated otherwise in a credit line to the material. If material is not included in the article's Creative Commons licence and your intended use is not permitted by statutory regulation or exceeds the permitted use, you will need to obtain permission directly from the copyright holder. To view a copy of this licence, visit http://creativecommons.org/licenses/by/4.0/.

\section{References}

Aghaei H, Ghosh S, Behrghani KH (2020) Example of applied outcrop analysis and its significance as an analogue for surrounding giant gas-fields; case study of Kuh-e-Surmeh region, southwestern Iran. Ore Energy Resour Geol 4-5:100010

Al-Khaldy MD, Dutta A, Al-Failakawi KA, Al-Bateni AE, Chimirala V, Elsherif A (2015) Petrophysics for horizontal wells with sourceless lwd technology, a case study from Kuwait. SPE172541-MS, SPE Middle East Oil and Gas Show and Conference held in Manama, Bahrain

Amorocho C, Langford C, Warot G, Kerr E, and Ambrose R (2019). Improving Production in child wells by identifying fractures with an LWD ultrasonic imager: a case study from an unconventional Shale in the U.S. Paper presented at the SPWLA 60th Annual Logging Symposium

Attenuation resistivity. Retrieved on 6th June 2021 from http://www. glossary.oilfield.slb.com/en/Terms/a/attenuation_resistivity.aspx

Brady JL, Kohring JJ, and North RJ (1996) Improved production log interpretation in horizontal wells using pulsed neutron logs. Paper SPE 36625, SPE annual technical conference and exhibition held in Denver, CO.

Brady JL, Watson BA, Warner DW, North RJ, Sommer DM, Colson, JL, Kleinberg RL, Walcott DS, Sezginer A (1998) Improved Production Log Interpretation in Horizontal Wells Using a Combination of Pulsed Neutron Logs, Quantitative Temperature Log Analysis, Time Lapse LWD Resistivity Logs and Borehole Gravity. Paper SPE 46222, Western Regional Meeting held in Bakersfield, CA

Craig DP, Hoang T, Li H, Magness J, Ginn C, Auzias V (2021) Defining hydraulic fracture geometry using image logs recorded in the lateral of horizontal infill wells. In: Unconventional resources technology conference, Houston, 26-28 July, DOI https://doi. org/10.15530/urtec-2021-5031

Ellis D (1987) Well logging for earth scientists. Elsevier Science Publishing Company, Amsterdam, p 197

Ghosh S, Slatt RM (2019) Tectonic joint size, abundance, and connectivity: examples from Woodford Shale and Hunton Limestone. Shale Shaker-J Oklahoma City Geol Soc 70(3):112-136

Ghosh S, Hooker JN, Bontempi CP, Slatt RM (2018) High-resolution stratigraphic characterization of natural fracture attributes in the Woodford Shale, Arbuckle Wilderness and US-77D Outcrops, Murray County, Oklahoma. SEG Interpret 6(1):29-41

Gong B, Manuel E, Liu Y., Forand, D., Malizia T., Tohidi V., Saldana A (2021) Interpretation of LWD acoustic borehole image log: case studies from North American shale plays. SPWLA 62nd Annual logging symposium held online from May 17-20, 2021

Griffiths R, Morriss C, Ito K, Rasmus J, and David M (2012) Formation evaluation in high angle and horizontal wells-a new and practical workflow. SPWLA 53rd Annual logging symposium, Cartagena, Colombia

Hagiwara T (2006) Measuring horizontal resistivity RH in horizontal well logging. SEG/New Orleans 2006 annual meeting

King J (2018) Optimizing well productivity: horizontal logs unlock critical geologic knowledge. J Petrol Technol 70(11):18-21

Kinoshita T, Wago T, Tohda M, Sakiyama N, Kajikawa Y, Endo T, Bammi S, Wells P, Velez E, Shigekane A, Wada Y (2016) Quantifying anisotropy for completion optimization in shale using dipole sonic logging. SPE annual technical conference and exhibition, Dubai doi: https://doi.org/10.2118/181316-MS

Li K, Gao J, Ju X, Sun H (2018) Improved horizontal well logging porosity calculation for a gas reservoir in the Northern Ordos Basin, China. J Geophys Eng 15(5):2266-2277. https://doi.org/ 10.1088/1742-2140/aac866

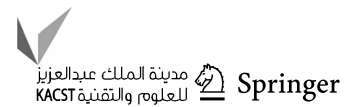


Liu S, Lucas JL, Plemons PA, Zhou X, Zett A, Spain DR, Rabinovich M, Pour RA, Zhou Q (2015) Challenges to geosteering and completion optimization of horizontal wells in the cotton valley formation East Texas. SPE Res Eval Eng 18(04):590-598

Mahiout S, Liu C, Polinski R, Moshood K (2020) Advanced resistivity modeling to enhance vertical and horizontal well formation evaluation. SPE 203347, Abu Dhabi International Petroleum Exhibition and Conference, Abu Dhabi, UAE. doi: https://doi.org/10.2118/ 203347-MS

Market J, Canady W (2009) Multipole sonic logging in high-angle wells. SPWLA-2009-33311 50th annual logging symposium, The Woodlands, Texas

Milad B, Ghosh S, Slatt R, Marfurt K, Fahes M (2020) Practical aspects of upscaling geocellular geological models for reservoir fluid flow simulations: a case study in integrating geology, geophysics, and petroleum engineering multiscale data from the Hunton Group. Energies 13:1604. https://doi.org/10.3390/en13071604

Milad B, Ghosh S, Suliman M, Slatt R (2018) Upscaled DFN models to understand the effects of natural fracture properties on fluid flow in the Hunton Group tight Limestone. In: Proceedings of the unconventional resources technology conference, Houston, TX, pp. 1193-1208

Morys M, Knizhnik S, Duncan AR, Tingey BE (2018) Advances in borehole imaging in unconventional reservoirs. SPE/AAPG/SEG Unconventional resources technology conference, Houston, Texas, USA. https://doi.org/10.15530/URTEC-2018-2903065

Omeragic D, Polyakov V, Shetty S, Brot B, Habashy T, and Flugsrud TL (2013) Workflow to automatically update geological models during well placement with high angle and horizontal well log interpretation results. In: SPE digital energy conference and exhibition held in The Woodlands, Texas, USA

Ortenzi L, Dubourg I, Van Os R, Han SY, Koepsell R, Ha CSY (2012) New azimuthal resistivity and high-resolution imager facilitates formation evaluation and well placement of horizontal slim boreholes. Petrophysics 53(2012):197-207

Pajchel BS, Hansen MD, Galta S, Thorsen AK, Kurz G (2011) Petrophysical Interpretation Using Magnetic Resonance in North Sea Horizontal Wells. In: SPWLA-2011-U presented at the SPWLA 52nd annual logging symposium, Colorado Springs, CO.

Passey QR, Yin H, Rendeiro CM, Fitz DE (2005) Overview Of HighAngle And Horizontal Well Formation Evaluation: Issues, Learnings, And Future Directions. In: SPWLA 46th annual logging symposium, New Orleans, Louisiana

Phase-shift resistivity. Retrieved on 6th June 2021 from http://www. glossary.oilfield.slb.com/en/Terms/p/phase-shift_resistivity.aspx

Polyakov V, Omeragic D, Shetty S, Brot B, Habashy T, Mahesh A, Friedel T, Vik T, Flugsrud TL (2013) Reservoir characterization workflow integrating high angle and horizontal well log interpretation with geological models. In: IPTC16828, International petroleum technology conference held in Beijing, China, 26-28 March

Rogtec (2017) https://rogtecmagazine.com/rosneft-new-approach-welllogging-data-horizontal-deviated-wells/

Drilling sideways - a review of horizontal well technology and its domestic application (1994, April). Retrieved from http://www. eia.gov/pub/oil_gas/natural_gas/analysis_publications/drilling_ sideways_well_technology/pdf/tr0565.pdf
Singer JM (1992) An example of log interpretation in horizontal wells. SPWLA-1991-v33n2a1 published in the log analyst

Sun K, Morriss C, Rasmus J, Ito K, Asif S, Griffiths R, Maggs D, Omeragic D, Crary S, Aria A (2014) Automated resistivity inversion for efficient formation evaluation in high-angle and horizontal wells. In: SPWLA 55th annual logging symposium, Abu Dhabi, United Arab Emirates

Syofyan S, Hanif MS, Latief AI, El Gazar AL, Al-Shabibi TA, Boesing D, Deng L, Fernandes W, Soliman AM, Smart C (2017) New method of improving formation evaluation in high-angle or horizontal wells using image-constrained inversion. In: SPE 188795, Abu Dhabi international petroleum exhibition and conference, Abu Dhabi, UAE. doi: https://doi.org/10.2118/188795-MS

Thorsen AK, Eiane T, Thern HF, Fristad P, Williams S (2010) Magnetic resonance in chalk horizontal well logged with LWD. SPE Res Eval \& Eng 13(04):654-666

Valdisturlo A, Mele M, Maggs D, Lattuada S, Griffiths R (2013) Improved Petrophysical analysis in horizontal wells: from log modeling through formation evaluation to reducing model uncertainty - a case study. In: SPE164881, EAGE Annual conference and exhibition incorporating SPE Europec, London, UK. doi: https://doi.org/10.2118/164881-MS

Wang L, Liu Y, Caizhi W, Yiren F, Zhenguan WU (2021) Real-time forward modeling and inversion of logging while-drilling electromagnetic measurements in horizontal well. Pet Explor Dev 48(1):159-168

Wang R, Torres-Verdín C, Huang S, Herrera W (2015a) Interpretation of sonic waveforms acquired in high-angle and horizontal wells. Presented at the SPWLA 56th Annual Logging Symposium, Long Beach, California

Wang H, Tao G, Fehler MC, Miller D (2015b) The Wavefield of a multipole acoustic logging-while-drilling tool in horizontal and highly deviated wells. Presented at the SPWLA 56th Annual Logging Symposium, Long Beach, California

Wen XC, Tong FW, Yi Z, Bin NX, Han SY, and Zhao LJ (2013) Revolution of horizontal well formation evaluation to promote the deep and complex reservoir development-case studies from Tarim Basin, China. Paper presented at the SPWLA 19th formation evaluation symposium of Japan, Chiba, Japan

Worthington PF (2008) Formation evaluation in horizontal wells - the pivotal role of anisotropy. Petrophysics 49(4):331-341

Xu C, Stewart RR (2004) Identifying channel sand versus shale using 3C-3D seismic data, VSPs and horizontal well logs. In: EG International exposition and 74th annual meeting, Denver, Colorado

Zhou Q (2008) Log interpretation in high-deviation wells through userfriendly tool-response processing. Paper SPWLA-2008-AAAA presented at the 49th Annual Logging Symposium, Austin, TX

Publisher's Note Springer Nature remains neutral with regard to jurisdictional claims in published maps and institutional affiliations. 